\section{Toward Robust High Resolution Chemical Imaging}

Carlos A. Barrios, Andrey V. Malkovskiy, Alexander

Kisliuk, Alexei P. Sokolov, Mark D. Foster

Department of Polymer Science, The University of Akron, Akron, $\mathrm{OH}$ cab48@uakron.edu

Resonant plasmon excitations at the surface of noble metals can localize and amplify an electromagnetic field in a very small volume and are the enabling element of surface enhanced optical microscopies [1]. Tip enhanced Raman spectroscopy (TERS) combines scanning probe microscopy (SPM) with Raman spectroscopy, taking advantage of this enhancing mechanism [2]. So far a $20 \mathrm{~nm}$ lateral resolution in chemical imaging of a surface has been achieved. Unfortunately, pure noble metal nanostructures, the most active plasmon materials known, are fragile, and prone to mechanical, chemical, and morphological degradation (Fig 1). Means of protecting and extending the lifetime of these surfaces are key for making the plasmon-based high resolution chemical imaging a robust characterization technique.
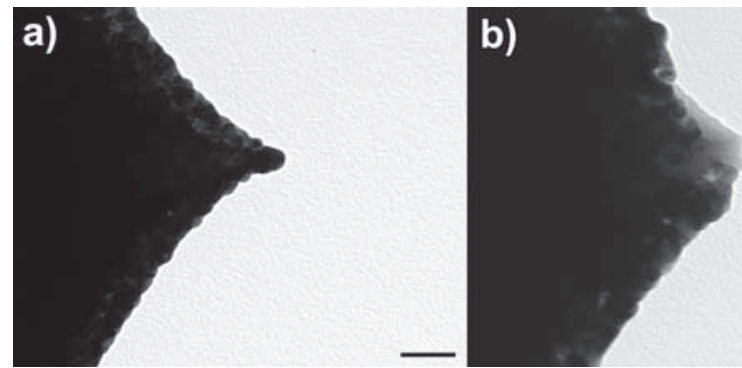

Figure 1. Transmission Electron Microscopy (TEM) images of an unprotected silver-coated SPM tips (a) before and (b) after scanning a polymer thin film three times. Mechanical degradation of the plasmonic structure by wearing is evident in Fig 1b. Scale bar is 100nm. Electron beam accelerating voltage $=120 \mathrm{kV}$.

Usually, a very rough noble metal nanostructure at the apex of a sharp SPM tip, also known as the plasmonic nanostructure, provides the signal amplification required for high resolution

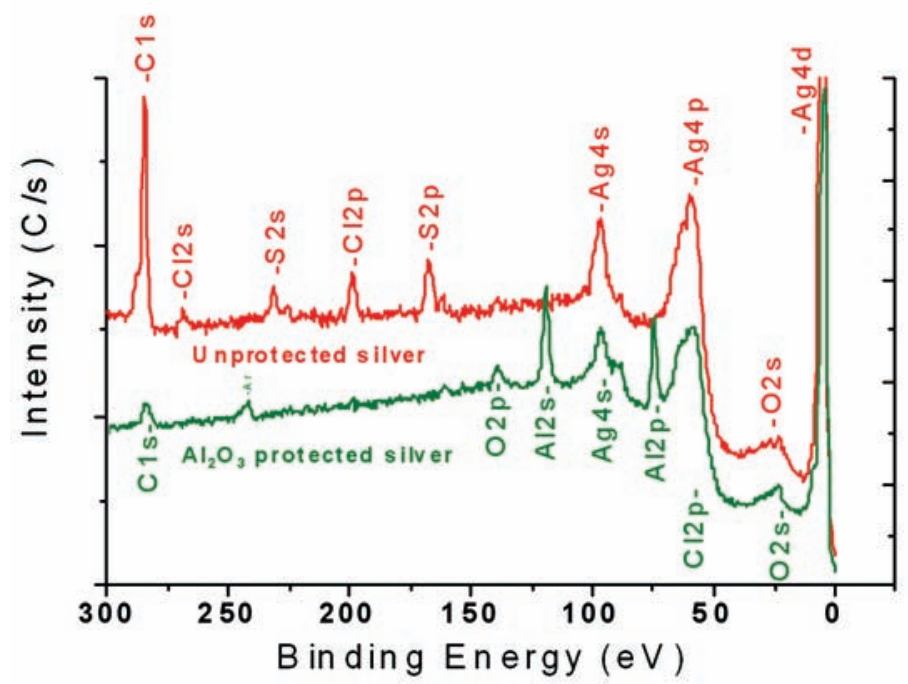

Figure 3. X-ray photoelectron spectra of silver plasmonic structures created on flat substrates after two months stored under ambient conditions: unprotected (upper curve) or protected by a $3 \mathrm{~nm}$ thick ultrathin $\mathrm{Al}_{2} \mathrm{O}_{3}$ coating (lower curve). The lower concentrations of carbon, sulfur, and chorine species evidence how the ultrathin $\mathrm{Al}_{2} \mathrm{O}_{3}$ layer drastically reduces chemical degradation.

chemical imaging. Plasmonic structure characteristics such as roughness, shape, and radius determine the spatial resolution and signal enhancement. Successful extension of the probe's active life requires stopping degradation processes while minimizing unfavorable influences on the optical response. Controlled physical vapor deposition (PVD) of aluminum can be used to create an ultrathin $\mathrm{Al}_{2} \mathrm{O}_{3}$ protective layer of a few nanometers on silver-coated SPM tips that dramatically improves chemical stability and wear resistance without sacrificing initial TERS efficiency [3]. Such a coating completely prevents decay in plasmonic activity over 40 days of use (Fig 2). A similar $\mathrm{SiO}_{\mathrm{x}}$ protective coating provides some lifetime improvement, but fails to stop degradation completely [4].

The plasmonic/air interface is not only the heart of the plasmon resonance enhancement, but also the focus of the degradation. Two flat plasmonic surfaces prepared at the same time, but in different
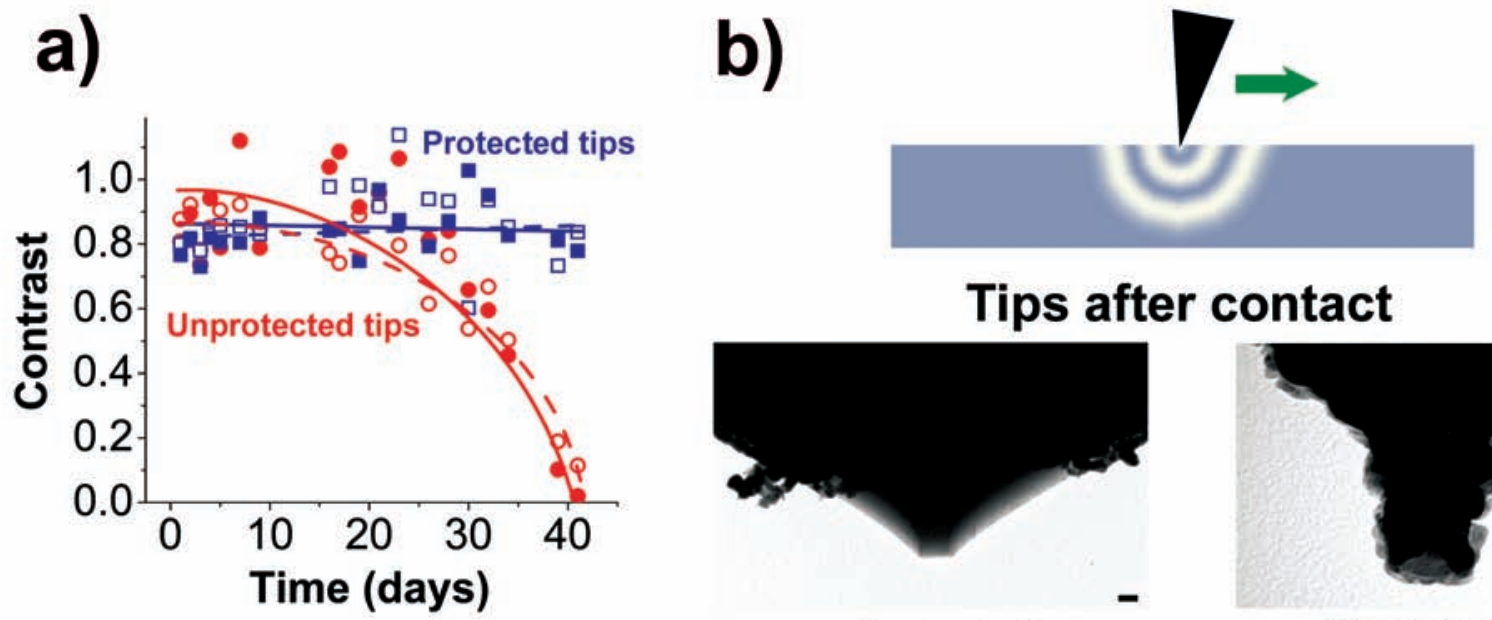

Tips after contact

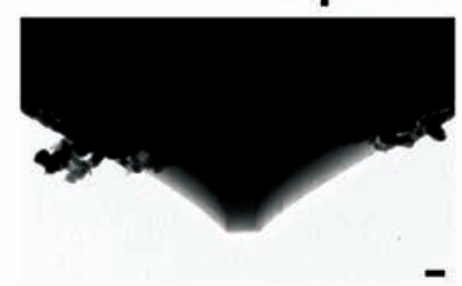

Protected

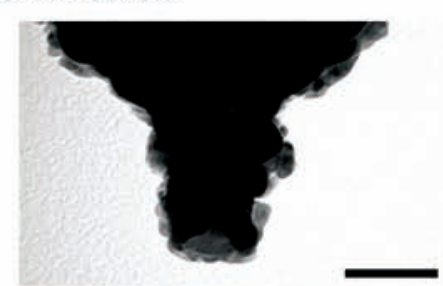

Unprotected

Figure 2. (a) TERS contrasts (measured at wave number $1450 \mathrm{~cm}^{-1}$ ) as a function of time for a $50 \mathrm{~nm}$ thick PEDOT/PSS film for unprotected silvercoated $\mathrm{Si}_{3} \mathrm{~N}_{4}$ tips (circles) and silver-coated $\mathrm{Si}_{3} \mathrm{~N}_{4}$ tips protected by a $3 \mathrm{~nm}$ thick $\mathrm{Al}_{2} \mathrm{O}_{3}$ thin layer (squares). Some tips were stored under ambient conditions (open symbols) and some inside a plastic desiccator under vacuum (filled symbols). (b) TEM images of an unprotected and a protected silver-coated SPM tip after scanning a polymer thin film three times. Scale bar is $50 \mathrm{~nm}$. Electron beam accelerating voltage $=120 \mathrm{kV}$. 
ways, one protected with a $3 \mathrm{~nm}$ thick $\mathrm{Al}_{2} \mathrm{O}_{3}$ layer and the other unprotected, were used to determine how chemical degradation, principally generated by sulfur containing gases in the atmosphere and promoted by atmospheric humidity, is affected by the presence of the ultrathin $\mathrm{Al}_{2} \mathrm{O}_{3}$ layer. XPS spectra measured after 2 months of storage under ambient conditions show sulfidation, one of the main reactions of silver tarnishing, but also contamination of the unprotected tip by water, carbonaceous material and chlorine (Fig 3). The spectrum for the protected surface shows no sulfidation, no chlorine, and a lower concentration of carbon, evidencing how the ultrathin $\mathrm{Al}_{2} \mathrm{O}_{3}$ layer drastically minimized chemical degradation.

\section{References}

[1] Wessel, J. J. Opt. Soc. Am. B 1985, 2, 1538

[2] Mehtani, D.; Lee, N.; Hartschuh, R. D.; Kisliuk, A.; Foster, M. D.; Sokolov, A. P. In Tip Enhancement. Advances in Nano-Optics and Nano-Photonics; Kawata, S., Shalaev, V. M., Eds.; Elsevier: New York, 2007; pp. 177-203.

[3] Barrios, C. A.; Malkovskiy, A. V.; Kisliuk, A. M.; Sokolov, A. P.; Foster, M. D. J. Phys. Chem. C 2009, Accepted for publication.

[4] Barrios, C. A.; Malkovskiy, A. V.; Hartschuh, R. D.; Kisliuk, A. M.; Sokolov, A. P.; Foster, M. D. Proc. SPIE-Int. Soc. Opt. Eng. 2008, 6954, $69540 \mathrm{C} / 1$.

[5] Research support from the Army Research Office (W911NF-07-1-0470) is gratefully acknowledged.

\section{MRS-5}

We are ISO-9000 certified and ISO-17025 accredited Microscopy Calibration Standard Now you can calibrate from $1,000 \mathrm{X}$ to $1,000,000 X !$

This is our fourth generation, traceable, magnification reference standard for all types (SEM, FESEM, Optical, STM, AFM, etc.) of microscopy. The MRS- 5 has multiple $\mathrm{X}$ and $\mathrm{Y}$ pitch patterns ranging from $80 \mathrm{~nm}( \pm 1 \mathrm{~nm})$ to $2 \mu \mathrm{m}$ and $3 \mathrm{bar}$ targets from $80 \mathrm{~nm}$ to $3 \mu \mathrm{m}$. There is also a STM test pattern.

Free web resource guide!
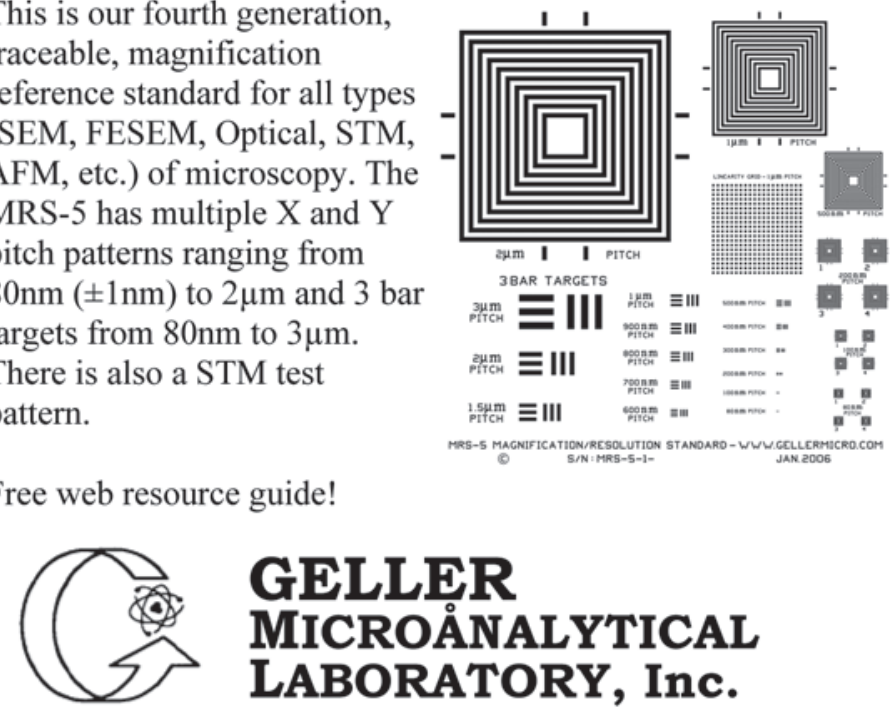

GELLER MICROÅNALYTICAL LABORATORY, Inc.

426e Boston St., Topsfield, Ma 01983 www.gellermicro.com

\section{FIVE GENERATIONS OF PERFORMANCE...REFINED}

\section{The all new Desk V sputtering tool.}

With an enhanced sputter head, larger mechanical pump*, a more powerful PLC and a lower price, the all new Desk V is generations ahead of the competition.

Features:

- Short deposition times

- Consistent deposition parameters

- Enhanced touchscreen controls

- Film thickness control

- Etch mode for sample cleaning

- Wide variety of coating materials

- Compact benchtop design
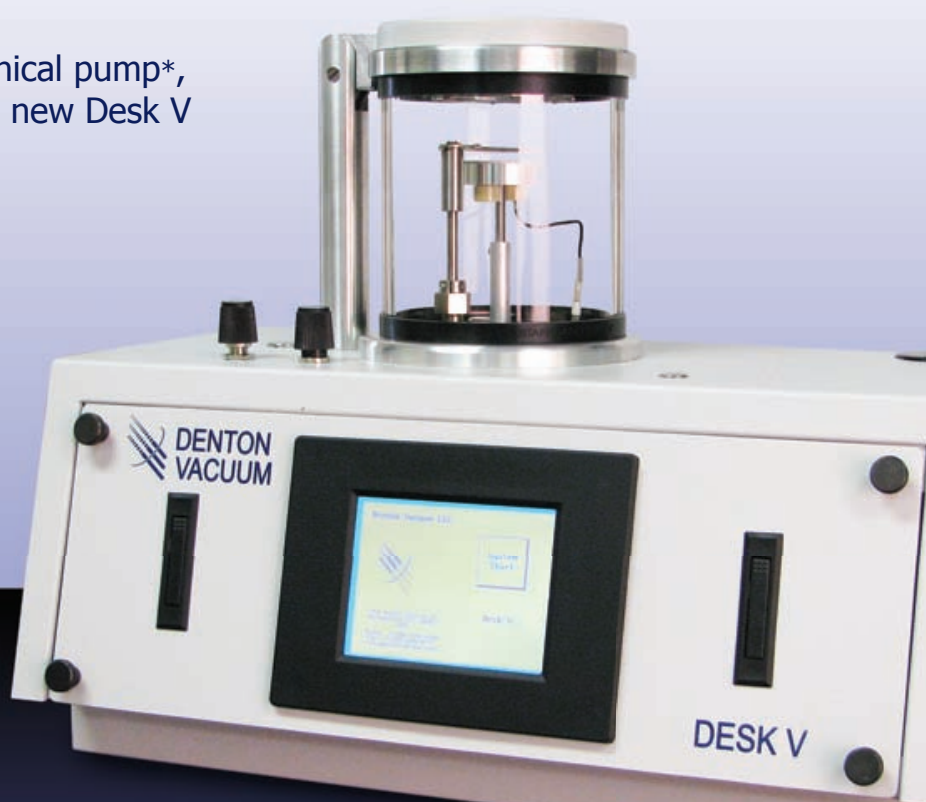

*mechanical pump is optional to allow a third party pump to be used at customer's discretion 